\title{
Knowledge about Radiation Related Health Hazards and Protective Measures among Patients Waiting for Radiologic Imaging in Jimma University Hospital, Southwest Ethiopia
}

\author{
Gemechis Asefa ${ }^{1}$, Wondim Getnet ${ }^{1}$, Tsegaye Tewelde ${ }^{2}$
}

ABSTRACT

BACKGROUND: Radiologic diagnostic and therapeutic procedures using ionizing radiation carry potential health risks. Hence, clients' knowledge about radiation would play a key role in reducing unnecessary imaging and its impacts. However, information on client's knowledge in low income countries specifically in the Ethiopian context has been was limited. Therefore, the aim of this study was to assess knowledge about radiation related hazards and protective measures among patients waiting for radiologic imaging.

METHODS: Descriptive cross sectional study design was employed on 388 patients waiting for radiologic imaging in Jimma University Hospital from Dec.25/2014 to Jan. 10/2015. Eligible participants were interviewed using pretested questionnaire. Data were entered and analyzed using IBM SPSS version 21. A descriptive analysis was conducted to get summary values of clients' radiation related knowledge.

RESULTS: A total of 386 clients were included to the analysis.Two hundred and three (52.6\%) participants had ever heard radiation related health hazards. Among these, $74.9 \%$ mentioned infertility, 64.0\% indicated cancer followed by $26.6 \%$ who mentioned cataract as radiation related health hazards. A large number of clients (75.6\%) had no idea about radiation protective measures, whereas $22 \%$ of them mentioned not entering examination room unless ordered by health professionals and $10.6 \%$ indicated covering sensitive body parts with lead $(\mathrm{pb})$. The majority (85.8\%) of the clients did not support unjustified repeated radiation imaging for diagnostic or other purposes.

CONCLUSION: The overall knowledge of clients about radiation imaging seems inadequate. Thus, comprehensive awareness raising programmes targeted at different settinsg and levels should be designed and implemented.

KEYWORDS: Radiation imaging, Knowledge, Radiation health hazards, Protective measures, Ethiopia

DOI: http://dx.doi.org/10.4314/ejhs.v26i3.5

\section{INTRODUCTION}

Radiation is energy that propagates through matter or space in the form of wave or particulate (1). Radiation can be classified into ionizing and nonionizing. Non-ionizing radiation does not have enough energy to produce ions (2), whereas ionizing radiation has the ability to knock electrons off atoms, thereby changing its chemical properties $(2,3)$. Likewise, there are four types of ionizing radiation: alpha radiation $(\alpha)$, beta radiation $(\beta)$, photon radiation (gamma $[\gamma]$ and $X-$ ray) and neutron radiation (n) (3).

Ionizing radiation comes from both natural and man-made materials $(2,3)$. From a total of $18 \%$ man-made radiations, around $15 \%$ exposures are due to the medical $x$-rays and nuclear medicine imaging $(4,5)$. The ionizing radiation that comes from man-made sources can be controlled and prevented, but there is little we can do for radiations that comes from natural sources $(2,3)$.

\footnotetext{
${ }^{1}$ Department of Radiology, College of Health Sciences, Jimma University, Ethiopia

${ }^{2}$ Department of Epidemiology and Biostatistics, College of Health Sciences, Jimma University, Ethiopia

Corresponding Author: Tsegaye Tewelde, Email: tsegaye.tewelde@yahoo.com
} 
Radiology departments in health institutions use different imaging modalities: both ionizing radiation (such as x-ray, fluoroscopy, mammography, and nuclear medicine and computer tomography) and non-ionizing radiations (such as ultrasound, magnetic resonance imaging) for diagnostic and therapeutic purposes (6).

Ionizing radiation has a dangerous effect on human health $(2,3,7-11)$. Ionizing radiation affects human health by changing chemical properties of the human body $(2,4)$ resulting in cell death (deterministic) or by impairing cellular function resulting in the development of cancer (stochastic) $(2,3)$.

Currently, there are different preventive measures recommended by the international commission on radiological protection (ICRP) (12) to reduce radiation induced cancer and other health problems $(2,3,12,13)$. It was recommended that all patient exposures must be justified and kept as low as possible. Doses should also be limited.

Clients in governmental health institutions can push health professionals to take radiation imaging (14), and due to this and other factors, nearly $30 \%$ (14) of all radiologic examinations prescribed by physicians are not clinically significant. On the top of these, patients seeking health services from private clinics can selfrequest and get radiation imaging for diagnostic or other purposes since private clinics are usually business oriented (15-17). Hence, knowledge of clients about the health hazards of radiation imaging as well as protective measures would play a key role in reducing unnecessary imaging and its impacts as well as in utilizing protective measures persistently $(18,19)$. Previous studies conducted on clients in different corners of the world show inadequate knowledge and awareness about radiation health hazards $(18,19,20,21,22)$.

Despite the presence of adequate evidence about knowledge of ionizing and non-ionizing radiation imaging among health professionals and radiologists, information about knowledge of radiation related health hazards and protective measures among clients in low income countries specifically in the Ethiopian context has been limited. Therefore, the aim of this study was to assess knowledge about radiation related hazards and protective measures among patients waiting for radiologic imaging in Jimma University Specialized Hospital. The output of this study would help as an evidence for different organizations working on cancer and related health problems to design and implement programmes focusing on reducing unnecessary ionizing radiation imaging through raising community awareness.

\section{METHOD AND PARTICIPANTS}

Study Setting: Data were collected from December $25 / 2014$ to January $10 / 2015$ on patients waiting to have diagnostic imaging at the Radiology Department, Jimma University Specialized Hospital (JUSH), Jimma Town, Southwest Ethiopia. Jimma Town is located in Southwest Ethiopia, 335Km from Addis Ababa, the capital city of the country. The hospital is the only referral hospital in Jimma Zone, which serves for over 15 million people in Southwest Ethiopia (23). The Radiology Department gives service for all patients referred from different specialty departments. There were two x-ray machines, one fluoroscopy and three functional ultrasounds (one Doppler ultrasound) in this unit. Approximately more than 20,000 of patients are referred to this department per year for imaging which makes around 1660 patients per month and about 60 patients per day.

Study design: A facility based descriptive crosssectional study was employed. Clients' knowelge about radiation related health hazards and protective measures within a specific time period was the intention of this study. Hence, a cross sectional study design was implemented.

Participants: A sample of 388 eligible adult patients refereed from all departments of the hospital for diagnostic imagings using ionizing radiation were included in the survey. For a patient to be included to the survey, he/she had to be an adult who was not emergency or psychiatric case.

Sampling procedure: The sample size was calculated using single population proportion formula, by considering estimated proportion of clients who have awareness about radiation as $40 \%$ (21), with 95\% Confidence level, 5\% margin of error. On this bases and with the addition of $5 \%$ non-response rate, a total of 388 clients were 
required. Clients were consecutively included in the survey while they arrived in the waiting area of the Radiology Department. This continued until the required sample size was achieved.

Measurement: To assess clients' knowledge about ionizing radiation related health hazards, questions were asked about the types of imaging modalities they knew, the types of ionizing and non-ionizing modalities, the types of body organs sensitive for ionizing radiation, health hazards caused by radiation and safe imaging modalities for pregnant women. All the questions were responded as 'yes', 'no' or 'I do not know/have no idea'. Similarly, the items intended to measure knowledge of clients on protective measures of radiation included radiation protection symbol, types of radiation prevention measures and recommendation of repetitions of unjustified imaging. Other variables included in the study were socio-demographic characteristics of clients and history of radiation imaging.

Knowledge about any of the health hazards caused by radiation was defined as 'yes' if participants mentioned any of the following health hazards: infertility, cancer, cataract, decreased life expectancy, genetic/fetal anomalies or hair lose. Moreover, knowledge about any of the protective measures for radiation was defined as 'yes' if participants were able to mention any of the following protective measures: not entering exam room, covering sensitive part by lead (pb), preferring x-ray with small dose or no radiology at all, not supporting patient without pb cover, or wearing thick clothese. The interview questionnaire was prepared in English and translated into Amharic and Afaan Oromo languages and thereafter back translation was done by other persons to check the consistency.

Data were collected through face-to-face interview using interviewer administered structured questionnaire in two rooms of the Radiology Department. The instrument used to assess ionizing radiation related knowledge was adapted and modified by reviewing different literatures (18-21). Data collectors were two diploma-holding nurses recruited from employees at different units of the same hospital. However, all the investigators were assigned as supervisors.
A one-day training was given for data collectors. Next, the questionnaire was pre-tested on $5 \%$ of the sample before the actual data collection days in Shenen Gibe Hospital, a governmental hospital located in Jimma Town, Southwest Ethiopia. Necessary correction was made based on the pilot results .

Data processing and analysis: Data were edited manually before entry to a computer and entered in to IBM SPSS statistics version 20. Descriptive analysis was made to get summary values of knowledge about ionizing radiation related hazards, ionizing radiation protective measures, radiation imaging history, socio-demographic variables and check for outliers, inconsistencies and missed values. Finally, the result was presented in the form of tables.

Ethical consideration: Ethical clearance was obtained from the Health Research and Postgraduate Coordinating Office of the College of Public Health and Medical Sciences of Jimma University. Oral consent was obtained from the study participants. Consent form was developed by the research team and approved by the Ethical Committee of Jimma University. Similarly, the information was handled confidentially and it was used only for research purpose. Care was taken not to interfere with the normal radiologic services given in the department.

\section{RESULTS}

Socio-demographic characteristics: From the total of 388 samples, two were found unwilling to participate in the interview. This made a response rate of $99.5 \%$. Then, a total of 386 samples with complete data were included in to the analysis (Table 1).

Two hundred and twenty-five $(58.3 \%)$ of the respondents were males. The median age of participants was 30 years and the majority (39.9\%) of them fell in the age group of 20-29 years. In educational status, $164(42.5 \%)$ attended primary school, whereas only $51(13.2 \%)$ attended college and above. One hundred and twelve (29.02\%) were self-employed, 260(67.4\%) were Muslim and 263(68.1\%) Oromo in ethnicity (Table1). 
Table 1: Socio-demographic characteristics and knowledge of clients waiting for radiologic imaging in Jimma University Specialized Hospital (n=386), Southwest Ethiopia, 2014

\begin{tabular}{|c|c|c|c|c|c|c|}
\hline \multirow[t]{2}{*}{ Variable } & \multirow[t]{2}{*}{ Category } & \multirow[t]{2}{*}{$\mathrm{N}(\%)$} & \multicolumn{2}{|c|}{$\begin{array}{l}\text { Know at least one } \\
\text { radiation health hazard }\end{array}$} & \multicolumn{2}{|c|}{$\begin{array}{l}\text { Know at least one } \\
\text { radiation protective } \\
\text { measure }\end{array}$} \\
\hline & & & Yes $(\%)$ & No $(\%)$ & Yes (\%) & No $(\%)$ \\
\hline Sex & $\begin{array}{l}\text { male } \\
\text { Female }\end{array}$ & $\begin{array}{l}225(58.3) \\
161(41.7)\end{array}$ & $\begin{array}{l}107(47.6) \\
71(44.1)\end{array}$ & $\begin{array}{l}118(52.4) \\
90(55.9)\end{array}$ & $\begin{array}{l}63(28.0) \\
31(19.3)\end{array}$ & $\begin{array}{l}162(72.0) \\
130(80.7)\end{array}$ \\
\hline Age in years & $\begin{array}{l}<20 \mathrm{yrs} \\
20-29 \mathrm{yrs} \\
30-39 \mathrm{yrs} \\
40-49 \mathrm{yrs} \\
\geq 50 \mathrm{yrs}\end{array}$ & $\begin{array}{l}51(13.2) \\
154(39.9) \\
73(18.9) \\
56(14.5) \\
52(13.5)\end{array}$ & $\begin{array}{l}22(43.1) \\
79(51.3) \\
37(50.7) \\
21(37.5) \\
19(36.5)\end{array}$ & $\begin{array}{l}29(56.9) \\
75(48.7) \\
36(49.3) \\
35(62.5) \\
33(63.5)\end{array}$ & $\begin{array}{l}12(23.5) \\
41(26.6) \\
17(23.3) \\
13(23.2) \\
11(21.2)\end{array}$ & $\begin{array}{l}39(76.5) \\
113(73.4) \\
56(76.7) \\
43(76.8) \\
41(78.8)\end{array}$ \\
\hline $\begin{array}{l}\text { Educational } \\
\text { status }\end{array}$ & $\begin{array}{l}\text { Illiterate } \\
\text { Primary school(1- }\end{array}$ & $\begin{array}{l}93(24.1) \\
164(42.5)\end{array}$ & $\begin{array}{l}21(22.6) \\
69(42.1)\end{array}$ & $\begin{array}{l}72(77.4) \\
95(57.9)\end{array}$ & $\begin{array}{l}13(14.0) \\
33(20.1)\end{array}$ & $\begin{array}{l}80(86.0) \\
131(79.9)\end{array}$ \\
\hline & $\begin{array}{l}\text { Secondary } \\
\text { school }(9-12)\end{array}$ & $78(20.2)$ & $50(64.1)$ & $28(35.9)$ & $25(32.1)$ & $53(67.9)$ \\
\hline & $\begin{array}{l}\text { Collage and } \\
\text { above }\end{array}$ & $51(13.2)$ & $38(74.5)$ & $13(25.5)$ & $23(45.1)$ & $28(54.9)$ \\
\hline $\begin{array}{l}\text { Occupational } \\
\text { status }\end{array}$ & $\begin{array}{l}\text { Self-employed } \\
\text { House wife } \\
\text { Farmer } \\
\text { Government and/ } \\
\text { private employee }\end{array}$ & $\begin{array}{l}112(29.02) \\
85(22.02) \\
79(20.47) \\
61(15.80)\end{array}$ & $\begin{array}{l}68(60.7) \\
26(30.6) \\
21(26.6) \\
45(73.8)\end{array}$ & $\begin{array}{l}44(39.3) \\
59(69.4) \\
58(73.4) \\
16(26.2)\end{array}$ & $\begin{array}{l}34(30.4) \\
10(11.8) \\
13(16.5) \\
30(49.2)\end{array}$ & $\begin{array}{l}78(69.6) \\
75(88.2) \\
66(83.5) \\
31(50.8)\end{array}$ \\
\hline & $\begin{array}{l}\text { Student } \\
\text { Others }\end{array}$ & $\begin{array}{l}31(8.03) \\
18(4.66)\end{array}$ & $\begin{array}{l}13(41.9) \\
5(27.8)\end{array}$ & $\begin{array}{l}18(58.1) \\
13(72.2)\end{array}$ & $\begin{array}{l}5(16.1) \\
2(11.1)\end{array}$ & $\begin{array}{l}26(83.9) \\
16(88.9)\end{array}$ \\
\hline Religion & $\begin{array}{l}\text { Muslim } \\
\text { Orthodox } \\
\text { Protestant } \\
\text { Others }\end{array}$ & $\begin{array}{l}260(67.4) \\
72(18.7) \\
52(13.5) \\
2(0.5)\end{array}$ & $\begin{array}{l}107(41.2) \\
35(48.6) \\
35(67.3) \\
1(50)\end{array}$ & $\begin{array}{l}153(58.8) \\
37(51.4) \\
17(32.7) \\
1(50)\end{array}$ & $\begin{array}{l}56(21.5) \\
17(23.6) \\
20(38.5) \\
1(50)\end{array}$ & $\begin{array}{l}204(78.5) \\
55(76.4) \\
32(61.5) \\
1(50)\end{array}$ \\
\hline Ethnicity & $\begin{array}{l}\text { Oromo } \\
\text { Amhara } \\
\text { Keffa } \\
\text { Others }\end{array}$ & $\begin{array}{l}263(68.1) \\
70(18.1) \\
30(7.8) \\
23(6.0)\end{array}$ & $\begin{array}{l}118(44.9) \\
39(55.7) \\
10(33.3) \\
12(52.2)\end{array}$ & $\begin{array}{l}145(55.1) \\
31(44.3) \\
20(66.6) \\
11(47.8)\end{array}$ & $\begin{array}{l}65(24.7) \\
15(21.4) \\
6(20.0) \\
8(34.8)\end{array}$ & $\begin{array}{l}198(75.3) \\
55(78.6) \\
24(80.0) \\
15(65.2)\end{array}$ \\
\hline
\end{tabular}

Information and referral to radiologic imaging: Regarding the referring unit for the current diagnostic imaging, nearly half $(49.2 \%)$ of the respondents were from Internal Medicine and $141(36.5 \%)$ were from surgery units. More than half of the respondents had previous radiologic unit visited for imaging. Among these, nearly half
(49.8\%) had both x-ray and ultrasound. Unfortunately, nearly a quarter $(28.2 \%)$ of the respondents got information about radiation from the current referring units, while half of the participants got background information about radiation from different sources (Table 2). 
Table 2: Information on and referral to radiologic imaging and knowledge among clients waiting for radiologic imaging in Jimma University Specialized Hospital $(n=386)$, Southwest Ethiopia, 2014

\begin{tabular}{|c|c|c|c|c|c|c|}
\hline \multirow[t]{2}{*}{ Variable } & \multirow[t]{2}{*}{ Category } & \multirow[t]{2}{*}{$\mathrm{N}(\%)$} & \multicolumn{2}{|c|}{$\begin{array}{l}\text { Know at least one } \\
\text { radiation health hazard }\end{array}$} & \multicolumn{2}{|c|}{$\begin{array}{l}\text { Know at least one } \\
\text { radiation protective } \\
\text { measure }\end{array}$} \\
\hline & & & Yes $(\%)$ & No (\%) & Yes $(\%)$ & No (\%) \\
\hline \multirow[t]{5}{*}{$\begin{array}{l}\text { Referring unit for } \\
\text { current imaging }\end{array}$} & $\begin{array}{l}\text { Internal } \\
\text { medicine }\end{array}$ & $191(49.5)$ & $73(38.2)$ & $118(61.8)$ & $38(19.9)$ & $153(80.1)$ \\
\hline & $\begin{array}{l}\text { Gynecology and } \\
\text { obstetrics }\end{array}$ & 41(10.6) & $23(56.1)$ & $18(43.9)$ & $12(29.3)$ & $29(70.7)$ \\
\hline & Surgery & $141(36.5)$ & $76(53.9)$ & $65(46.1)$ & $41(29.1)$ & $100(70.9)$ \\
\hline & Ophthalmology & $8(2.1)$ & $5(62.5)$ & $3(37.5)$ & $3(37.5)$ & $5(62.5)$ \\
\hline & Others & $5(1.3)$ & $1(20.0)$ & $4(80.0)$ & 0 & $5(100)$ \\
\hline Previous & Yes & $197(51)$ & $110(55.8)$ & $87(44.2)$ & $67(34.0)$ & $130(66.0)$ \\
\hline $\begin{array}{l}\text { radiologic } \\
\text { imaging }\end{array}$ & No & 189 (49) & $68(36.0)$ & $121(64.0)$ & $27(14.3)$ & $162(85.7)$ \\
\hline Types of previous & X-ray(all types) & $69(35)$ & $36(52.2)$ & $33(47.8)$ & $21(30.4)$ & $48(69.6)$ \\
\hline radiologic & Ultrasound & $30(15.2)$ & $16(53.3)$ & $14(46.7)$ & $11(36.7)$ & $19(63.3)$ \\
\hline $\begin{array}{l}\text { imaging used } \\
(n=197)\end{array}$ & Both & $98(49.8)$ & $58(59.2)$ & $40(40.8)$ & $35(35.7)$ & $63(64.3)$ \\
\hline Got radiation & Yes & $109(28.2)$ & $90(82.6)$ & $19(17.4)$ & $50(45.9)$ & $59(54.1)$ \\
\hline $\begin{array}{l}\text { information from } \\
\text { the referring unit }\end{array}$ & No & $277(71.8)$ & $88(31.8)$ & $189(68.2)$ & $44(15.9)$ & $233(84.1)$ \\
\hline Got radiation & Yes & $193(50)$ & $161(83.4)$ & $32(16.6)$ & $89(46.1)$ & $104(53.9)$ \\
\hline $\begin{array}{l}\text { background } \\
\text { information from } \\
\text { different sources }\end{array}$ & No & $193(50)$ & $17(8.8)$ & $176(91.2)$ & $5(2.6)$ & $188(97.4)$ \\
\hline
\end{tabular}

Knowledge about radiation related health hazards: Three hundred and fifty-six $(92.2 \%)$ and $284(73.6 \%)$ of the clients were familiar with conventional x-ray and ultrasound respectively. However, 29(7.5\%) the participants did know any imaging modalities. Likewise, 140(36.3\%) of them mentioned conventional $\mathrm{x}$-ray as an ionizing radiation modality, but $244(63.2 \%)$ of them had no idea. On the other hand, $65(16.8 \%)$ and $32(8.3 \%)$ of the clients incorrectly assumed that ultrasound and MRI examinations are classified under ionizing radiation modalities (Table 3).

With regard to radiation related health hazards, more than half $(52.6 \%)$ of the participants had ever heard of radiation related health hazards. Among these, nearly $3 / 4^{\text {th }}(74.9 \%)$ mentioned infertility, almost $2 / 3^{\text {rd }}(64.0 \%)$ indicated cancer, nearly $1 / 4^{\text {th }}(26.6 \%)$ mentioned cataract followed by nearly one-in-ten $(10.3 \%)$ mentioned short life span as radiation related health hazards. On the top of these, most of (59.8\%) the respondents had no idea about the sensitive organs for radiation, whereas almost $1 / 3^{\text {rd }}(31.6 \%)$ mentioned gonads as sensitive organs for radiation. However, the majority $(90.2 \%)$ of the clients had no idea about the safe imaging modality during pregnancy. Few clients $(8.3 \%)$ mentioned ultrasound as a safe imaging modality during pregnancy. Very few $(1 \%)$ and $(1.3 \%)$ clients incorrectly mentioned plain abdominal x-ray and CT as safe for pregnant mothers respectively (Table 3 ). 
Table 3: Knowledge about radiation related health hazards among clients waiting for radiologic imaging in Jimma University Specialized Hospital (n=386), Southwest Ethiopia, 2014.

\begin{tabular}{|c|c|c|c|}
\hline Variables & Category & Frequency & Percentage \\
\hline \multirow[t]{6}{*}{ Types of radiologic imaging modalities } & Conventional x-ray & 356 & 92.2 \\
\hline & Ultrasound & 284 & 73.6 \\
\hline & MRI & 59 & 15.3 \\
\hline & CT & 76 & 19.7 \\
\hline & Mammography & 45 & 11.7 \\
\hline & Don't know & 29 & 7.5 \\
\hline \multirow[t]{5}{*}{ Types of modalities which uses ionizing radiation } & Radiography all type & 140 & 36.3 \\
\hline & Ultrasound & 65 & 16.8 \\
\hline & MRI & 32 & 8.3 \\
\hline & $\mathrm{CT}$ & 45 & 11.7 \\
\hline & No idea & 244 & 63.2 \\
\hline \multirow[t]{7}{*}{ Possible health hazards caused by radiation } & Infertility & 152 & 74.9 \\
\hline & Cancer & 130 & 64.0 \\
\hline & Cataract & 54 & 26.6 \\
\hline & Life shortening & 21 & 10.3 \\
\hline & Hair loss & 17 & 8.4 \\
\hline & $\begin{array}{l}\text { Genetic/fetal } \\
\text { anomaly }\end{array}$ & 10 & 4.9 \\
\hline & No Idea & 183 & 47.4 \\
\hline \multirow{5}{*}{ Human body organs highly sensitive for Radiation } & Gonads & 122 & 31.6 \\
\hline & Kidney & 27 & 7.0 \\
\hline & Thyroid & 5 & 1.3 \\
\hline & Breast & 1 & 0.3 \\
\hline & No idea & 231 & 59.8 \\
\hline \multirow[t]{5}{*}{ Safe imaging modalities for pregnant } & Ultrasound & 32 & 8.3 \\
\hline & CT & 5 & 1.3 \\
\hline & $\begin{array}{l}\text { Plain abdominal } \mathrm{x}- \\
\text { ray }\end{array}$ & 4 & 1 \\
\hline & MRI & 4 & 1 \\
\hline & No idea & 348 & 90.2 \\
\hline Ever heard of back ground radiation related health & Yes & 19 & 4.9 \\
\hline hazards & No & 369 & 95.1 \\
\hline
\end{tabular}

Almost half $(47.6 \%)$ of males, $51.5 \%$ of $20-29$ year-olds, almost $3 / 4^{\text {th }}(74.5 \%)$ of those who had college and above education, and $73.8 \%$ of government and private employees were able to mention at least one of the health hazards caused by radiation imaging respectively (Table 1). Nearly half $(56.1 \%)$ of the participants referred were from Gynecology and Obstetrics units; $55.8 \%$ of the participants who had experience of radiologic imaging and $82.6 \%$ of them who got information about radiation from the referring unit were able to mention at least one of the protective measures for radiation respectively (Table 2).

Knowledge about protective measures of radiation: With regard to the protective measures, only few $(3.9 \%)$ of the patients knew radiation protection symbols. A large number of them (75.6\%) responded that they had no idea about protective or precautionary measures during diagnostic imaging. Nearly two-in-five (22\%) mentioned not entering into examination room unless ordered by health professionals, one in ten 
$(10.6 \%)$ indicated covering the sensitive body parts with lead $(\mathrm{pb})$ and $8.5 \%$ prefered $\mathrm{x}$-ray with small dose or no radiology at all as protective measures. Another important point which needs attention was their belief that wearing thick clothes protects radiation exposure as indicated by $15(3.6 \%)$ patients. However, the majority $(85.8 \%)$ of the clients did not support unjustified repeated radiation imaging for diagnostic or other purposes (Table 4).

Table 4: Knowledge about protective measures of radiation among clients waiting for radiologic imaging in Jimma University Specialized Hospital (n=386), Southwest of Ethiopia, 2014.

\begin{tabular}{llll}
\hline Variable & Category & Frequency & Percentage \\
\hline Know about radiation protection symbol & Yes & 15 & 3.9 \\
& No & 371 & 96.1 \\
Protective measures for radiation & Do not enter exam room & 85 & 22.0 \\
& Cover sensitive part lead(pb) & 41 & 10.6 \\
& Prefer x-ray with small dose or no & 33 & 8.5 \\
& radiology & & \\
& Do not support patient without pb & 25 & 6.5 \\
& cover & & \\
& Wear thick cloth & 14 & 3.6 \\
& No idea & 292 & 75.6 \\
Repetition of unjustified radiation imaging & Yes & 55 & 14.2 \\
is recommended & No & 331 & 85.8 \\
Ionizing radiation application other than & Radiotherapy & 10 & 2.6 \\
imaging & Lithotripsy & 6 & 1.6 \\
& Other* & 2 & 0.6 \\
& No idea & 371 & 96.1 \\
\hline
\end{tabular}

Other* is security, energy \& light

Twenty-eight percent of males, $45.1 \%$ of participants who were college and above in education, and almost half $(49.2 \%)$ of government/ private employees knew at least one of the radiation protective measures respectively (Table 1). Likewise, nearly $1 / 3^{\text {rd }}(34.0 \%)$ participants who had experienceed of radiologic imaging, 30.4\% participants who had X-ray imaging experience and $45.9 \%$ participants who got information about radiation imaging from the refereeing unit knew at least one protective measure for radiation respectively (Table 2).

\section{DISCUSSION}

This institution based cross sectional study was planned to assess the patients' knowledge about radiation related health hazards and protective measures. More than half $(52.6 \%)$ of the participants had ever heard of radiation related health hazards. Among these, nearly $3 / 4^{\text {th }}$ and $2 / 3^{\text {rd }}$ of them mentioned infertility and cancer as the radiation related health hazards.

Regarding radiation related health hazards, more than half $(52.6 \%)$ of the participants had ever heard of radiation related health hazards. This was higher than the findings in Iraq (18\%) (18), Nigeria (13\%) (21) and Uganda (43\%) (19). This variation could be attributed to the small sample in all the previous studies, difference in rephrasing the question (Have you heard of radiation related health hazards? Vs. Do you know radiation related health hazards?). It also might be due to variation in socio-demographic characteristics of the participants. However, it was not promising compared to the as low as reasonably achievable (ALARA) principles and ICRP recommendations $(2,12)$.

Nearly $75 \%$ and $26.6 \%$ of the participants who had ever heard of the health hazards mentioned that infertility and cataract can be caused by radiation respectively. In addition, 
$64.0 \%$ of the participants indicated cancer could be the consequence of radiation imaging. However, this was inconsistent with the study done in Turkey (73.2\%) (20). This could be attributed to the small sample a nsociodemographic and economic variation of participants in Turkey. On top of this, most of (59.8\%) the respondents had no idea about the sensitive organs for radiation, but $31.6 \%$ mentioned gonads as a sensitive organ for radiation.

These might indicate awareness raising programmes about radiation related health hazards are missing in Jimma Zone and may be in the country at large. If these remains unresolved, clients might continue either pushing health care providers to order or self-request radiation imaging and by instigate health risks.

The majority (90.2\%) of the clients had no idea about the safe imaging modality during pregnancy. However, this finding was higher than the figure in Turkey (73.2\%) (20). This might be due to difference in socio-demographic and economic characteristics of the two population and in the sample size. However, few clients (8.3\%) correctly mentioned ultrasound as safe imaging modality during pregnancy. These findings imply that clients were unaware of safe radiation imaging during pregnancy. Thus, they may push health professionals to use any available radiation equipment for diagnostic or other purposes.

As to the background radiation related health hazards, $95.1 \%$ of the participants had not ever heard of health hazards related to background radiation. Hence, there is a need to comprehensively incorporate all other possible sources of radiation in addition to diagnostic and therapeutic ones on community or patient awareness raising programmes.

Concernig the protective measures, a large number of patients $(75.6 \%)$ responded that they had no idea about protective measures or precaution during diagnostic imaging. This was almost consistent with the Ugandan study (83.3\%) (19), whereas $22 \%$ mentioned not entering into examination room unless ordered by health professionals, and $10.6 \%$ indicated covering the sensitive body parts with lead (pb). On the other hand, wearing thick clothes to protect radiation exposure was indicated by $3.6 \%$ of the patients, which was again very much lower than a study done in Turkey (22.3\%) (20). This might show limited role of health professionals in the referring departments, as well as professionals in the radiologic unit. But this could actually be easy and affordable strategy to aware clients about radiation health hazards.

Fortunately, the majority $(85.8 \%)$ of the clients did not support unjustified repeated radiation imaging for diagnostic or other purposes. This was higher than the finding from Nigeria (70\%) (21). This could be the result of limited sample size and variation in population sociodemographic characteristics. This seems promising in reducing the health hazards as a result of repeated and unjustified radiation imaging in our set up.

In conclusion, promising background radiation related information and refusal of repeated and unjustified radiation imaging were identified. Nearly half of the clients had ever heard of radiation related health hazards, $3 / 4^{\text {th }}$ of them reported infertility as a radiation related health hazard. Besides, $3 / 4^{\text {th }}$ of the clients had no idea about radiation protective/preventive measures; however, nearly a quarter of those mentioned not entering into examination room unless ordered by health professionals.

The overall knowledge of clients about radiation related health hazards and the protective measures seems inadequate. Hence, comprehensive awareness raising programmes targeted at different settings, including community, governmental and private health institutions should be designed and implemented. Besides, large scale research should be conducted to validate and produce normative data on the overall radiation related knowledge of clients at community and private clinics. 


\section{REFERENCES}

1. Oak Ridge Institute for Science and Education. ORISE: Radiation emergency assistance center/training site (REAC/TS): Guidance for radiation accident management. [https://orise.orau.gov/reacts/], accessed October 2014.

2. Ministry of public works and government service Canada: Keeping radiation exposure and dose "As Low as Reasonably Achievable (ALARA)" Regulatory guide G-129, Revision 1. Canada: Canadian nuclear safety commission; 2004.

3. UNSCEAR (2006): Effect of ionizing radiation: Report to the General assembly, with scientific Annexes. United Nations Publication; ISBM 978-92-1-142263-4, http://www.unscear.org/unscear/en/publications /2006_1.html, accessed October 2014.

4. United States Nuclear Regulatory Commission. U.S.NRC: Radiation and National Security. [http://www.nrc.gov/about-nrc/radiation/radnat-security.html], accessed October 2014.

5. Kajal M VK, Chetana R, Sandeep D. Consultant's knowledge and awareness about radiation exposure in diagnostic radiology in Central India .International Journal of Biomedical Research, 2015; 6(01):14-18.

6. Rebecca S-B, Jafi L, Ralph M, et al. Radiation Dose Associated With Common Computed Tomography Examinations and the Associated Lifetime Attributable Risk of Cancer. Archives of Internal medicine, 2009; 169(22)

7. Seife T D, Daniel A, Yenework E. Assessment of Final-Year Medical Students and Interns Awareness of Radiation Exposure to Common Diagnostic Imaging procedures. Hindawi Publishing Corporation Advances in Radiology, 2014; 2014:7

8. Wang JX, Zhang L A, Li B X, et al. Cancer incidence and risk estimation among medical $\mathrm{X}$ ray workers in China, 1950-1995. Health Phys, 2002; 82(4):455-466.

9. Goldberg Z, Schwietert CW, Lehnert B, Stern R, Nami I. Effects of low-dose ionizing radiation on gene expression in human skin biopsies. Int J Radiat Oncol Biol Phys, 2004; 58(2):567-574.
10. Arslanoglu A, Bilgin S, Kubal Z, Ceyhan MN, Ilhan MN, Maral I. Doctors' and intern doctors' knowledge about patients' ionizing radiation exposure doses during common radiological examinations. Diagn Interv Radiol, 2007; 13(2):53-55.

11. Borretzen I, Lysdahl KB, Olerud HM. Diagnostic radiology in Norway trends in examination frequency and collective effective dose. Radiat Prot Dosimetry, 2007; 124(4):339-347.

12. International Commission on Radiological Protection: The 2007 Recommendations of the International Commission on Radiological Protection: ICRP Publication 103. ELSEVIER; 2007

13. Mubeen SM, Abbas Q, Nisar N. Knowledge about ionising and non-ionising radiation among medical students. J Ayub Med Coll Abbottabad, 2008; 20(1):118-121.

14. Suresh S, Rajagopal KV, Sabu KM. PERCEPTION OF RADIATION AWARENESS AMONG MEDICAL DOCTORS IN INDIA. International Journal of Pharmacy and Biological Sciences, 2013; 3(3):371-376.

15. Institute of Medicine: For-Profit Enterprise in Health Care. Washington DC: National Academy Press; 1986.

16. Institute of Medicine: The New Health Care for Profit: Doctors and Hospitals in a Competitive Environment. Washington DC: National Academy Press; 1986.

17. Mark S. The Rise of Proprietary Health Care. Business and Health, 1985; 2: 7-12

18. Haider NA, IBMS F, MRD D. Patient's Awareness of Cancer Risk from Radiation in Computerized Tomography. Kufa MedJournal 2011; 14(1)

19. Malwadde EK, Matovu PD, Kawooya MG, Byanyima RK. Radiation Safety Awareness among Radiation Workers and Clients at Mulago Hospital, Kampala, Uganda. East and Central African Journal of Surgery, 2006; 11 (1)

20. Aylin Y, Emel K, Emre B, Ilker K, Berna D, Aslihan O. Knowledge about Ionizing Radiation and Radiation Protection Among Patients Awaiting Radiological Examinations: 
A cross-sectional survey. The Medical Journal of Kocatepe, 2009; 10:25-31.

21. Margaret A-K, Polycarp C, Valentine B-P. Radiation Safety Awareness among patients and Radiographers in three Hospitals in Port Harcourt Am J Sci Ind Res, 2013; 4(1):83-88.

22. Lee CI, Haims AH, Monico EP, Brink JA, Forman HP. Diagnostic CT scans: assessment of patient, physician, and radiologist awareness of radiation dose and possible risks. Radiology, 2004; 231(2):393-398.

23. Jimma University: Jimma University specialized Hospital (JUSH). [http://www.ju.edu.et/jimma-universityspecialized-hospital-jush], accessed October 2014. 